\title{
nature
}

\section{How to help universities meet obligation and opportunity}

A landmark report on British higher education highlights an undercapitalized system ever more driven by a growing diversity of customers and the breakdown of trust between the academic community and the state.

$\mathrm{T}$ he arrival of mass higher education in Britain — as in other industrialized countries - has been a mixed blessing for many of the institutions concerned. The desire that a continuously increasing proportion of the population should be able to benefit from a university course is unexceptional. But expansion has brought growing pressures, particularly as budgetary resources have not kept up either with the expanding teaching load or with the investment required to sustain across-the-board excellence in research.

As the National Committee of Inquiry into Higher Education, chaired by Sir Ron Dearing, reported last week (see page 413), there are serious problems that need to be addressed if universities are properly to fulfil the new roles and responsibilities that have been placed on them. Some will require more money, and it was inevitable that the government's main response to the Dearing committee's report focused on its decision to end an era of free university tuition. Others, however, will require cultural and attitudinal changes in universities themselves, and it is on the government's ability to stimulate and secure these changes without major disruption that its success in implementing Dearing's recommendations will be judged.

At the heart of these changes is the question of trust. 'Old style' higher education was based on an unwritten contract between universities and the state, at the core of which was the concept of academic freedom - the idea that universities should be entirely free to choose what to teach and what to research. Appropriately, this purity has been abandoned, but the trust implicit in this contract has also disappeared under increasing demands for demonstrable value for money. No longer is it accepted that what is good for universities is good for the country.

This breakdown of trust has had its own unfortunate consequences. Some are manifest in excessive demands for accountability from the research community, resulting in hours spent filling in forms that could be more productively spent at the laboratory bench. In turn, many researchers feel under pressure to base their research and fund-seeking strategies on maximizing personal, relatively short-term gain, regardless of whether this is in the long-term interests of their institutions, or indeed of those they work with (reflected, for example, in the use of funds allocated for overheads to pay for short-term research assistants with little reflection on their longer-term career prospects).

Can this trust be rebuilt? Four years ago, the government sought in a white paper (policy document) to redefine the missions of the research councils in terms of an explicit commitment to wealth creation and the quality oflife. Many of Dearing's complementary recommendations for universities are expected to be taken up in a new white paper on higher education due in the autumn. Both initiatives reflect pressure for structural changes in the relationship between the research community and the state. But both will be undermined if a proper balance is not restored between freedom and accountability.

How can a proper partnership be re-established? The government can display its commitment by providing the financial support essential for maintaining the health and vitality of the science base. It is dangerous to use figures of current performance, based on previous invest- ment, to deflect charges of underfunding. The real value of such figures lies in demonstrating the cost-effectiveness of British science - and thus the potential gains to be had from new investment.

On the scientists' side, there is a need to combine a commitment to scientific excellence (judged now by international standards) with clear-headed strategic thinking. On the first, Dearing's suggestion that foreign researchers be invited to participate in the Research Assessment Exercise is to be welcomed, provided that their input is tempered with an acknowledgement of the other dimensions of the value of research.

As to the second, part of the value of instigating a more rigorous approach to the refunding of indirect costs is that it will encourage universities to check more robustly where this money does in fact go. The Dearing report itself emphasizes the need to ensure that the temptation to use overhead costs to fund research rather than infrastructure is "strenuously avoided". Medical charities' reluctance to cover indirect costs is based not on principle, but on the inability of universities to demonstrate that the money is not being used to replace the chapel roof.

There are inevitably prices to be paid for moving towards both greater selectivity and more strategic thinking. An excessively rigorous commitment to excellence always risks creating difficulties for those at the bottom of the ladder. It is essential that any attempt to distinguish between 'teaching' and 'research' departments still enables individuals to move flexibly between the two roles. And there remains a lack of imaginative suggestions as to how teaching performance can be awarded the same credit as research achievement - indeed what universities can do to give teaching the status and rewards that it deserves.

Another danger lies in the extra administrative burden created by a combination of tighter cost control, increased public accountability, and even strategic planning itself. The additional work-load must not rest excessively on researchers whose strongest skills and talents lie elsewhere. Funding bodies must be convinced that the extra administrative costs are themselves a legitimate overhead. It is surely no coincidence that those US universities that charge the highest overheads are also the most scientifically productive.

Finally, industry must not be let off the hook. There is a clear logic in the insistence of industrial leaders that it is the government's responsibility - not theirs - to ensure the health of the nation's science base. It is also clear that, where self-interest is high, industry will remain keen to build links with groups that meet its immediate needs. More difficult, but no less vital, is private sector support for generic initiatives whose benefits lie between the two; here, a whole-hearted commitment to initiatives such as Dearing's proposed Industrial Partnership Development Fund would be a welcome sign of good faith.

The main message of the Dearing report is the need for a new 'compact' between the different stakeholders with an interest in the continued health of British universities. If the language is uncomfortable to some, this is a measure of its novelty rather than its inappropriateness. But rebuilding both trust and commitment, on all sides, is the real, if at times painful, task facing the UK government as it works out how to respond. 